\title{
Design and Performance Evaluation of a Stone Crusher
}

\author{
Sulaiman, I., Egbe, E.A.P., Abdullahi, M., Saraki, Y.A. and Shehu, I.A.
}

\begin{abstract}
Crushers are essential machines in several industries for particle size reduction. They are invaluable in laboratories (higher institutions and research centres), the mining and construction industries. Available crushers are imported and very expensive. This has pushed some workers around Nigeria to crush stones with crude materials and manual labour, to meet the demand of the various sectors while neglecting the hazards involved. A hammer mill has been designed with due considerations to standard design requirements, local content and cost. The power required to crush granite with the desired through put of $400 \mathrm{~kg} / \mathrm{h}$ was found to be $5.5 \mathrm{~kW}$. Major factors considered for the material selection are the mechanical properties, wear of materials, fabrication requirement and cost. The machine was fabricated using locally available materials. The fabricated stone crusher was tested and the actual capacity was found to be $301 \mathrm{~kg} / \mathrm{h}$ with a through-put efficiency of $75.4 \%$. The crushed products were well graded with 1.89 coefficient of gradation and uniformity coefficient of 10.22. The machine was produced at a cost of two hundred and forty-five thousand, two hundred naira ( $\$ 245,200.00\{\mathrm{US} \$ 595.15\}$ ).
\end{abstract}

Keywords: Design analysis, Impact energy, Particle size, Performance evaluation, Uniformity coefficient.

\section{Introduction}

Reduction of solid particles is achieved by crushing, grinding, cutting and vibrating [1]. Particle reduction is a paramount aspect of a lot of industries; it is used for aggregate production to build infrastructure, in the mining industry, the agricultural and even in the pharmaceutical industry. As Nigeria actively seeks ways to diversify the economy, mining is an industry that will aid the achievement of this goal. The estimated worth of unexplored mineral resources available in the country runs into hundreds of trillions of Naira [2]. There can be no meaningful exploration without large scale exploration machines available at affordable cost. With the constant population rise and the need to satisfy housing and decent infrastructure

\begin{tabular}{l}
\hline Sulaiman, I., Abdullahi, M. and Saraki, Y.A (Department of \\
Mechanical Engineering, Federal Polytechnic Bida, \\
Nigeria.) \\
Egbe, E.A.P. (Department of Mechanical Engineering, \\
Federal University of Technology Minna, Nigeria) \\
Shehu, I.A. (Niger State Ministry of Transport, Niger State, \\
$\quad$ Nigeria) \\
Corresponding author: $\underline{\text { skishk2009@gmail.com }}$ \\
Telephone Number: $+234-806-862-3048$
\end{tabular}

problems, aggregates will be sought to solve these problems.

Aggregate production with the current techniques available may not be meeting the high demand available in Nigeria. Crushing stones with crude implements is very much being practised in different work sites around the country, this is a tedious, ineffective and timeconsuming activity [1]. The use of crude implements for stone crushing is prevalent in different locals around the country, it often causes deforestation as firewood is burnt to aid in the manual breaking process since burning causes the formation of microcracks in the rocks [3]. It is of note that the few crushers available in research institutes and universities/polytechnics in this country are imported and very expensive [4].

Solid particle reduction machines are often categorised under crushers [5], grinders, ultrafine grinders [6] or cutters [7]. The most common crushers are jaw, gyratory, ball mill and impact 
crusher. Jaw crushers are designed to look like jaws with a fixed and swing jaw; the swing jaw moves back and forth relative to the fixed one and thereby causes the crushing. The gyratory is similar in concept to the jaw crusher but has a concave and conical head instead of jaws. In a ball mill, the particles to be crushed are placed in a container with steel balls which are then rolled together. As for the impact crushers the particles to be crushed are contained within a cage and are then impacted with hammers continuously till the desired size is achieved [7, 8]. Impact crushers are the latest breed of crushers in use. They are considered the most effective for particle reduction [9].

A stone crusher has been developed to reduce the effort expended in aggregate formation and help preserve the environment. The machine is fabricated from locally available materials; this will ensure a reduction in the overall production cost, enhance local expertise, reduce dependency on foreign importation and aid in boosting the economy.

\section{Materials and Method}

\section{A. Machine Description and Working Principle}

The machine was designed with a hopper as depicted in Figure 1. To collect the feed for crushing. It was welded and subsequently fastened to the upper part of the crushing chamber. This will enable ease of maintenance when the need arises.

A set of 24 hammers in total was designed. There is a major shaft carrying the whole hammer assembly as seen in Figure 2, with 6 each arranged on 4 smaller shafts. A metallic pipe (stopper) is provided between each hammer to avoid the sliding movement of hammers in action. A sieve of $10 \mathrm{~mm}$ is provided underneath the stone to prevent stones of higher sizes from passing through. As the machine is switched on, the particles are fed in through the hopper and are immediately impacted by the moving

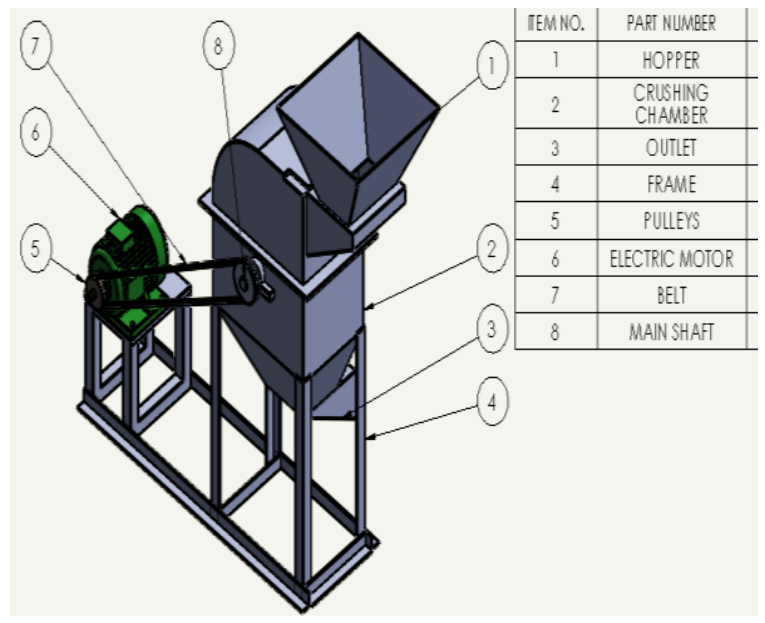

Figure 1: Isometric projection of the hammer mill working drawing

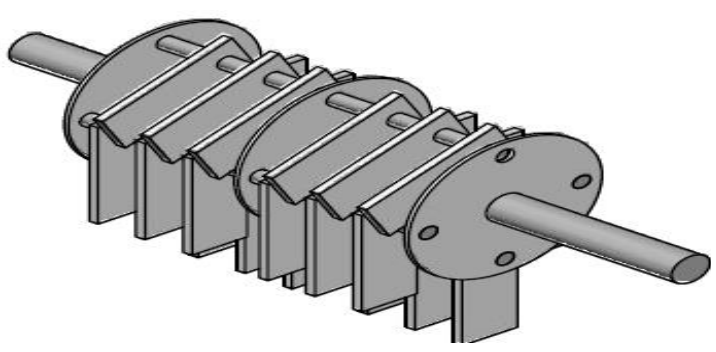

Figure 2: Hammer assembly

hammers. An impact plate is provided directly at the line of the impact that aids the crushing process. The stones will not be able to exit the chamber due to the installed sieve until the desired size is obtained. Multiple screen sizes may be used depending on the size needed. A hinge is provided that will allow access to the hammer unit for maintenance purposes.

\section{B. Design Analysis and Calculations}

Crushing may be achieved by means of either applying a compressive or impact force on a solid particle [5]. Equation (1) is used for estimating the crushing energy required to reduce the size of a solid particle that is coarse in nature. It is often referred to as Kick's law [6]. 


$$
E=k_{k} \operatorname{In}\left(\frac{x_{f}}{x_{p}}\right)
$$

where $k_{K}$ is the Kick's coefficient, $\mathrm{x}_{\mathrm{f}}$ and $\mathrm{x}_{\mathrm{p}}$ are feed and product sizes respectively in $\mathrm{mm}$.

\section{i. Design Considerations}

Some basic specification is provided herewith; $400 \mathrm{~kg} / \mathrm{h}$ is the target capacity for the machine and must be dust-tight to reduce the propagation of dust produced due to the crushing process.

\section{ii. Determination of the Energy Requirement}

The feed size and product size specifications for this work are $50 \mathrm{~mm}$ and $10 \mathrm{~mm}$ respectively and granite is the material to be used for performance evaluation. The average work index of granite is $16.6 \mathrm{kWh} / \mathrm{t}$ [10] and its compressive strength is $200 \mathrm{MN} / \mathrm{m}^{2}$ [11]. The energy required to crush coarse particles is provided by a modified Kick's equation [6].

$$
E=\frac{P}{\dot{m}}=k_{k} C_{s} \ln \left(\frac{x_{f}}{x_{p}}\right)
$$

where, $\mathrm{P}$ is the power needed to crush the stone in $\mathrm{W}, \dot{\mathrm{m}}$ is the feed rate in $\mathrm{kg} / \mathrm{s}, k_{k}$ is the Kick's coefficient, $C_{s}$ is compression strength of the material in $\mathrm{MPa}$ and $x_{f}$ and $x_{p}$ are inlet feed and outlet product sizes in $\mathrm{mm}$ respectively. $\mathrm{P}$ is obtained as $1.72 \mathrm{~kW}$, and subsequently the energy as $4.3 \mathrm{~kJ}$

The design power is obtained by considering a service factor of $2[8]$.

Design power $\left(\mathrm{P}_{\mathrm{D}}\right)=S_{f} \times P$

where $\mathrm{S}_{\mathrm{f}}$ is the Service factor and $\mathrm{P}$ is the required power in W. Electric motors rarely provide a $100 \%$ efficiency rating in selecting one, the efficiency must be considered. Electric motors in the power range of 1 to 4 hp have an efficiency of 0.84 [12]. This is adequate as $P_{D}$ was obtained as $3.4 \mathrm{~kW}$. The values were slotted into Equation (4) [12].

$$
\eta_{m}=\frac{P_{D}}{P_{\text {in }}}
$$

Thus;

Power in put $=\frac{3440}{0.84}=4095.2 \mathrm{~W}$ or $5.48 \mathrm{hp}$

The nearest higher power and available electric motor of $7.5 \mathrm{hp}$ was selected for the machine.

\section{iii. Determination of Hammer Plate Dimensions}

The maximum shear stress required to crush granite will be half its compressive strength, (that is $100 \mathrm{MPa}$ ) by applying the maximum shear stress theory of failure [13]. The maximum area resisting crushing of a $50 \mathrm{~mm}$ diameter stone is its cross-sectional area, $\pi r^{2}$. The stress acting on the stone is given Equation (5) as given by [13].

$$
\sigma_{\text {crushing }}=\frac{F_{1}}{A}
$$

where $\sigma_{\text {crushing }}$ is the crushing stress in $\mathrm{MPa}, \mathrm{F}_{1}$ is the force resisting crushing in $\mathrm{N}$ and $\mathrm{A}$ is the area in $\mathrm{m}^{2}$.

$$
F_{1}=100 \times 10^{6} \times \pi 0.025^{2}=196.35 \mathrm{kN}
$$

If the hammer plate is not to shear relative to the stone, then its material resistance to tear $\left(\mathrm{F}_{2}\right)$ must be greater than $F_{1}$. Adopting available $\mathrm{SAE}$ 1010 (cold drawn) steel and the same maximum shear stress theory, a shear strength of $150 \mathrm{MPa}$ was obtained. The load on the hammer plate varies from zero to a maximum impact load. Thus, a factor of 1.5 was used to account for the fatigue effect and ensure that the material resistance of plate $\left(\mathrm{F}_{2}\right)$ is greater than $\mathrm{F}_{1}$. This implies that,

$$
F_{2}=\frac{150}{1.5} \times 10^{6} \times b \times t \geq F_{1}
$$

where $\mathrm{b}$ and $\mathrm{t}$ are the width and plate thickness respectively. Since there is only one equation, a width dimension of $100 \mathrm{~mm}$ was adopted [2] and the required thickness was determined.

$$
\frac{150}{1.5} \times 10^{6} \times 0.1 \times t=196,350
$$

Solving yields, $\mathrm{t}=19.64 \mathrm{~mm}$, say $20 \mathrm{~mm}$. 


\section{iv. Belt Selection and Analysis}

A belt drive is used in this design as it simplifies the design of the machine and reduces the cost. Table 1 is used to select a belt type B, considering the power determined.

Table 1: V-Belt Power Ranges.

\begin{tabular}{|c|c|c|c|c|}
\hline $\begin{array}{c}\text { Cross } \\
\text { section }\end{array}$ & $\begin{array}{l}\text { Load } \\
\text { of } \\
\text { drive } \\
(\mathrm{kW}) \\
\end{array}$ & $\begin{array}{l}\text { Recommended } \\
\text { min. pulley } \\
\text { pitch diam., d } \\
(\mathrm{mm})\end{array}$ & $\begin{array}{l}\text { Nominal } \\
\text { top } \\
\text { width, b } \\
(\mathrm{mm}) \\
\end{array}$ & $\begin{array}{c}\text { Nominal } \\
\text { thickness, } \\
\text { t (mm) }\end{array}$ \\
\hline A & $\begin{array}{c}0.75- \\
5\end{array}$ & 75 & 13 & 8 \\
\hline B & $2-15$ & 125 & 17 & 11 \\
\hline C & $7.5-75$ & 200 & 22 & 14 \\
\hline D & $22-50$ & 355 & 32 & 19 \\
\hline $\mathrm{E}$ & $30-190$ & 500 & 38 & 22 \\
\hline
\end{tabular}

Source [13]

According to [13] the twisting moment in $\mathrm{Nm}$ for belt drives is given by Equation (6).

$$
T_{s}=\left(T_{1}-T_{2}\right) R
$$

where $\mathrm{T}_{1}$ and $\mathrm{T}_{2}$ are tensions on tight and slack side in $\mathrm{N}$ and $\mathrm{R}$ is pulley radius in $\mathrm{m}$. The maximum belt tension is obtained from Equation (7).

$$
T=\sigma b t
$$

The allowable safe stress $\sigma$ is $2.1 \mathrm{MN} / \mathrm{m}^{2}$ as recommended by $[1,13]$, where $\mathrm{b}$ and $\mathrm{t}$ are the belt thickness and width are $17 \mathrm{~mm}$ and $11 \mathrm{~mm}$ respectively as seen in Table (1). $T_{1}$ is therefore obtained as $357.66 \mathrm{~N}$, it is the tension in the tight side while tension in the slack side is obtained from Equation 8.

$$
\frac{T_{1}}{T_{2}}=e^{\mu \theta_{1} \operatorname{cosec} \beta}
$$

where $\mu$ is coefficient of friction, $\theta$ is contact angle on small pulley and $\beta$ is half the angle of $\mathrm{V}$ pulley. Substituting and solving yields tension on the slack side of the belt $\mathrm{T}_{2}$ as $22.13 \mathrm{~N}$. The large pulley radius of $0.095 \mathrm{~m}$ is selected for the machine. Thus, the belt twisting moment is obtained as $\mathrm{T}_{\mathrm{s}}=31.08 \mathrm{Nm}$.

\section{v. Number of Belts Required}

Power transmitted by the hammer mill shaft is given by Equation (9) according to [1].

$$
P=\omega T_{S}=\frac{2 \pi N}{60} T_{S}
$$

where $\mathrm{N}$ is the speed of the shaft in revolution per minute (rpm). Thus, $P$ is obtained as $4.2 \mathrm{~kW}$. The power input obtained was $4.1 \mathrm{~kW}$ which is lower than the power transmitted by the shaft which is $4.2 \mathrm{~kW}$; therefore, one belt is required to transmit power for the crushing [1].

\section{vi. Belt Length Consideration}

Belt length is obtained using Equation (10) as stated by [13].

$$
\mathrm{L}_{\mathrm{B}}=\frac{\pi}{2}\left(\mathrm{D}_{1}+\mathrm{D}_{2}\right)+2 \mathrm{C}+\left(\frac{\mathrm{D}_{1}-\mathrm{D}_{2}}{4 \mathrm{C}}\right)^{2}
$$

$\mathrm{D}_{1}$ and $\mathrm{D}_{2}$ are the pulley diameters adopted as $0.19 \mathrm{~m}$ and $0.14 \mathrm{~m}$ respectively. $\mathrm{C}$ is the distance between the pulleys and is $0.41 \mathrm{~m}$.

Therefore, $\mathrm{L}_{\mathrm{B}}=1.34 \mathrm{~m}=1340 \mathrm{~mm}$

So, the belt type B with length $1346 \mathrm{~mm}$ is selected for the machine.

\section{vii. Determination of Shaft Diameter}

According to the American Society of Mechanical Engineers ASME design code for solid shaft with combine torsion and bending load is given by $[1,14]$;

$$
d^{3}=\frac{16}{\pi s_{s}} \sqrt{\left(M k_{b}\right)^{2}+\left(T k_{t}\right)^{2}}
$$

where $S_{s}$ is allowable shear stress for steel with keyway as $40 \mathrm{MN} / \mathrm{m}^{2}, \mathrm{~K}_{\mathrm{b}}$ is bending factor $=3$ (due to high level of shock and fatigue [13]), $\mathrm{K}_{\mathrm{t}}$ is torsion factor $=3$ (due to high level of shock [13]). $T$ is torque and has been obtained as 31.08 $\mathrm{Nm}$ and $\mathrm{M}$ is the maximum bending moment and is obtained from analysing free body diagram given in Figures (3) and (4).

To obtain the resultants for the vertical forces $R_{B V}$ and $R_{F V}$ at points $B$ and $F$ the sum of upward and downward forces is equated, then the moment about $\mathrm{A}$ is taken, $\sum M_{A}=0$. 


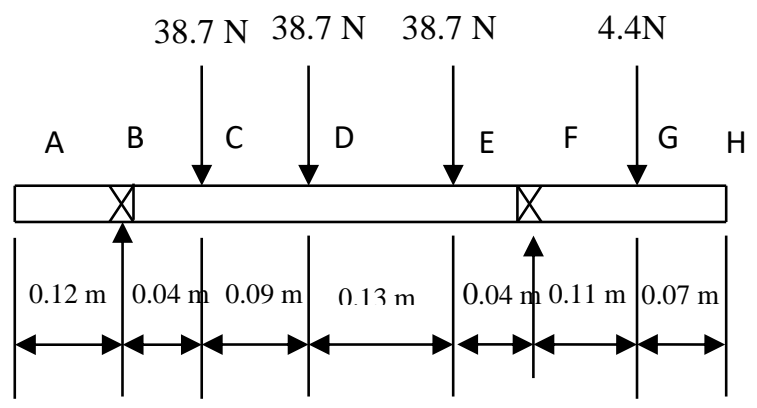

Figure 3: Vertical Forces Acting on the Shaft

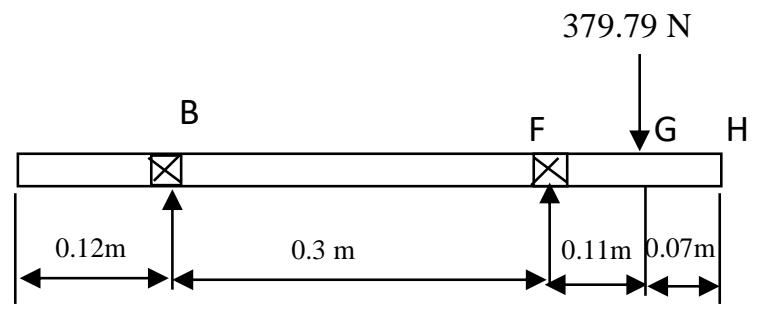

Figure 4: Horizontal Forces Acting on the Shaft

Using the same procedure as in the vertical forces the resultant bending moment was obtained for each point and is represented in the shear force and bending moment diagram in Figure (4)

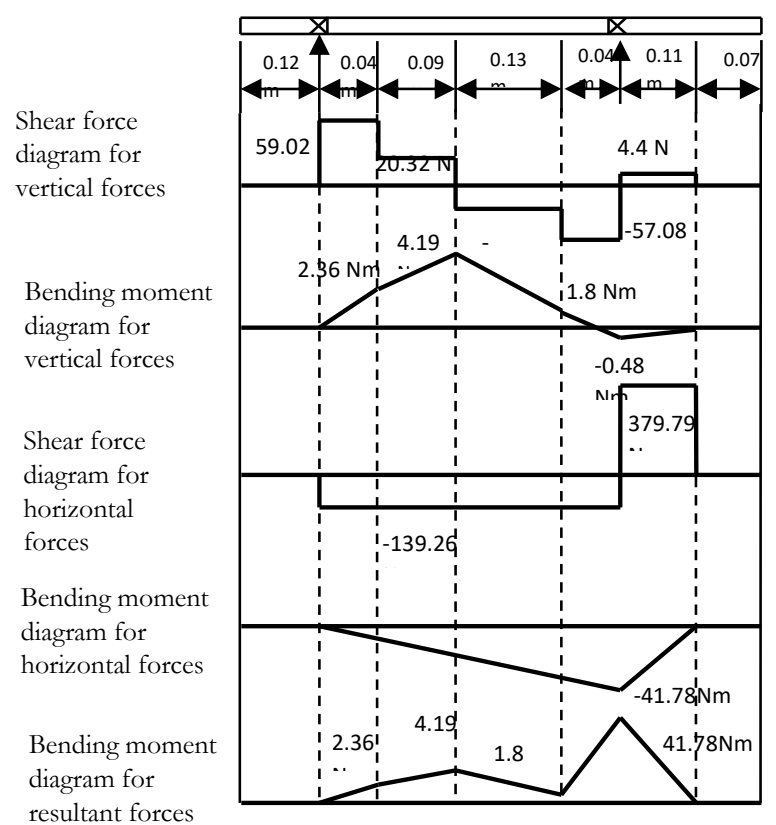

Figure 5: Shear Force and Bending Moment Diagrams

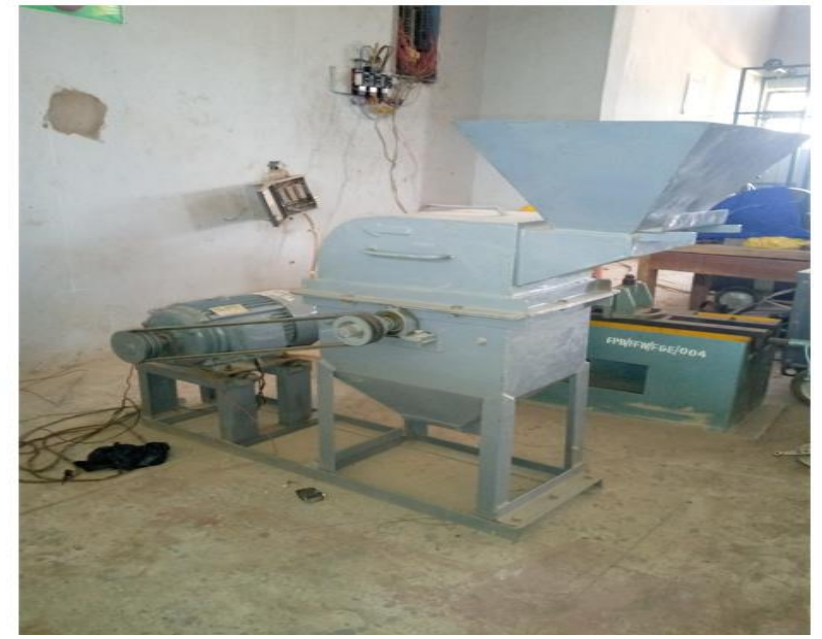

Figure 6: The Fabricated Stone Crusher

The resultant bending moment at point $\mathrm{F}$ is $41.78 \mathrm{Nm}$. Substituting known values into Equation (11) yields;

$d^{3}$

$=\frac{16}{\pi \times 40 \times 10^{6}} \sqrt{(41.78 \times 3)^{2}+(31.08 \times 3)^{2}}$

$\mathrm{d}=\sqrt[3]{1.99 \times 10^{-5}}$

$\mathrm{d}=0.02709 \mathrm{~m}=27 \mathrm{~mm}$ say $30 \mathrm{~mm}$.

Thus, shaft diameter selected for the machine is $30 \mathrm{~mm}$.

The fabricated machine is shown in Figure 6.

\section{Performance Evaluation of the Machine}

The type of stone used for the performance evaluation is granite with the recommended abrasion index of 0.388 [15] suitable for hammermills and due its availability and high usage for aggregates. Five tests were carried out in total with each initial feed weighing $3 \mathrm{~kg}$ per sample. Two separate tests were conducted; the crushing capacity of the machine and the product size distribution.

1. Crushing capacity: prior to loading each stone was ascertained to have a $50 \mathrm{~mm}$ average diameter using a $50 \mathrm{~mm}$ sieve, and weighed to give $3 \mathrm{~kg}$ before pouring into the hopper (for five (5) test runs). After the desired size is achieved the product is collected through the outlet. The crushing time and the weight after crushing were recorded. 
The Percentage material recovered after crushing $\mathrm{R}_{\mathrm{e}}$ (in \%) and percentage loss can be obtained from a modified Equation (12) and (13) from [2].

$$
\begin{aligned}
& R_{e}=\frac{\text { material mass output }}{\text { material mass input }} \times 100 \\
& \text { Percentage loss }=\frac{\text { mass input }- \text { mass output }}{\text { mass input }} \times 100
\end{aligned}
$$

The machine efficiency is given by Equation (14) [1], it is the ratio of the actual capacity obtained and the capacity the machine was designed for.

$$
M_{e}=\frac{\text { Actual capacity }}{\text { Design capacity }} \times 100
$$

2. Product size distribution analysis: the products samples each were sieved individually for each sample using the electrically powered sieve shaker unit. It is a U-Tech brand mild steel Rotap shaker with $0.25 \mathrm{hp}$ electric motor. The sieves used are of $10 \mathrm{~mm}, 6.30 \mathrm{~mm}, 3.35 \mathrm{~mm}$ and $2.0 \mathrm{~mm}$ sizes. Stones retained on the sieves were then used for analysis. The particle size distribution is expressed as a percentage retained by mass on each of the sieve sizes used [16].

$$
\% M R_{i}=\frac{M R_{i} \times 100}{T M}
$$

where $M R_{i}$ is individual mass retained in $\mathrm{kg}$ and TM is total mass in $\mathrm{kg}$.

The cumulative percent passing of the aggregate is found by subtracting the percent retained from $100 \%[16,17]$.

$$
\text { Cumm } \%_{i}=100-\% \text { Cumm retained }_{i}
$$

where Cumm $\%_{i}$ is the Cumulative percent passing for each sample in $\mathrm{kg}$ and $\%$ Cumm retained ${ }_{i}$ is the percentage cumulative retained for each sample in $\mathrm{kg}$.

The crushing capacity $\left(\mathrm{C}_{\mathrm{rc}}\right)$ is the mass of material crushed in $\mathrm{kg} / \mathrm{h}$ and is determined according to [2].

$$
\begin{gathered}
C_{r c}=\frac{\text { Average mass after crushing } \times \text { Time }(\mathrm{secs})}{\text { Average time taken to } \text { crush }} \\
C_{r c}=\frac{2.94 \times 3600}{35.2}
\end{gathered}
$$

Crushing Capacity, $\mathrm{C}_{\mathrm{rc}}=301.53 \mathrm{~kg} / \mathrm{h}$

The theoretical through-put efficiency $\varepsilon$ of the machine is determined from Equation (18) as provided by [2].

$$
\begin{aligned}
& \varepsilon=\frac{\text { Actual capacity }}{\text { Design capacity }} \\
& \qquad=\frac{301.53}{400}=0.754
\end{aligned}
$$

The values of the sieve analysis are presented graphically in Figure 6.

The equation for the percentage mass particles passing through the sieve is given by Equation (19) from the graph in Figure (6).

$$
y=-0.014 x^{4}+0.350 x^{3}-2.824 x^{2}+14.89 x-
$$

For $\mathrm{y}$ at $10 \%, \mathrm{D}_{10}$ will be obtained as $0.78 \mathrm{~mm}$ as demonstrated by $[15,17]$. At $y=30 \%$, then $\mathrm{D}_{30}$ will be $3.43 \mathrm{~mm}$ and lastly for y at $60 \%, \mathrm{D}_{60}$ will be $7.97 \mathrm{~mm}$. The uniformity coefficient $\left(\mathrm{C}_{\mathrm{u}}\right)$ was determined as 10.22 using Equation (20) while Equation (21) was used to obtain the coefficient of gradation $\left(C_{c}\right)$ as $1.89[15,17]$.

$$
\begin{aligned}
C_{u} & =\frac{D_{60}}{D_{10}} \\
C_{c} & =\frac{\left(D_{30}\right)^{2}}{D_{60} \times D_{10}}
\end{aligned}
$$

\section{Results and Discussion}

The results for the crushing test are presented in Table 2. It can be seen that it takes minimum time $(30.33 \mathrm{~s}$ ) to crush the materials with a 96.67 $\%$ recovery rate and the average mass of stone crushed by the machine is obtained as $2.94 \mathrm{~kg}$ while the average time taken is $35.1 \mathrm{~s}$.

The machine recovery rate is consistent considering the results obtained in Table 2. Only an average of about $2.8 \%$ is lost during the test runs. This might be as a result of debris during crushing and pulverised rocks being retained in the machine. 
Table 2: Material Mass Recovery and Crushing Time

\begin{tabular}{ccccc}
\hline $\begin{array}{c}\text { Test } \\
\text { Samples }\end{array}$ & $\begin{array}{c}\text { Mass } \\
\text { Before } \\
\text { Crushing } \\
\text { (kg) }\end{array}$ & $\begin{array}{c}\text { Mass } \\
\text { After } \\
\text { Crushing } \\
\mathbf{( k g )}\end{array}$ & $\begin{array}{c}\text { Time } \\
\text { Taken } \\
\mathbf{( s )}\end{array}$ & $\begin{array}{c}\text { Material } \\
\text { Recovered } \\
\mathbf{( \% )}\end{array}$ \\
\hline 1 & 3.00 & 2.90 & 30.33 & 96.67 \\
2 & 3.00 & 2.96 & 39.34 & 98.7 \\
3 & 3.00 & 2.90 & 36.37 & 96.67 \\
4 & 3.00 & 2.90 & 35.18 & 96.67 \\
5 & 3.00 & 2.96 & 34.69 & 98.7 \\
- & 3.00 & 2.94 & 35.18 & 97.2 \\
\hline
\end{tabular}

The theoretical through-put efficiency $\varepsilon$ of the machine is determined as $75.4 \%$ from Equation (18). The results obtained are favourable compared to those obtained by [18, 19]. Performance evaluation carried out by [18] on H2 commercial hammermills which had similar features to the fabricated stone crusher was able to achieve a capacity of $260 \mathrm{~kg} / \mathrm{h}$ crushing gold ore. The values of the sieve analysis are presented graphically in Figure 6.

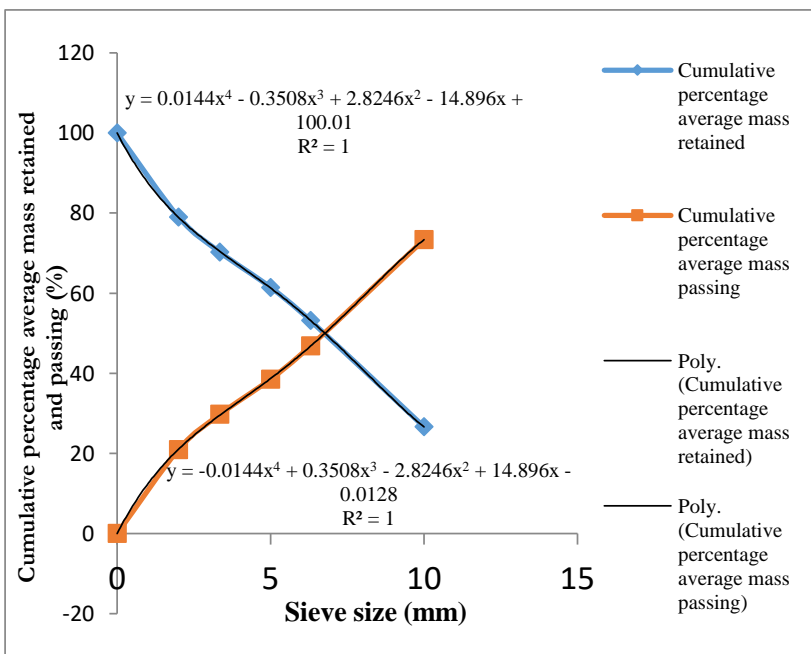

Figure 6: Sieve analysis graph of \% cumulative mass retained and passed for all sample average against the sieve size.

Equation (19) was used for analysing the percentage mass particles passing through the sieve.

$y=-0.014 x^{4}+0.350 x^{3}-2.824 x^{2}+14.89 x-$ 0.012

For $\mathrm{y}$ at $10 \%, \mathrm{D}_{10}$ will be obtained as $0.78 \mathrm{~mm}$ as demonstrated by $[15,17]$. At $y=30 \%$, then $\mathrm{D}_{30}$ will be $3.43 \mathrm{~mm}$ and lastly for $\mathrm{y}$ at $60 \%, \mathrm{D}_{60}$ will be $7.97 \mathrm{~mm}$. The uniformity coefficient $\left(\mathrm{C}_{\mathrm{u}}\right)$ was determined as 10.22 while the coefficient of gradation $\left(C_{c}\right)$ as 1.89 . The product is considered well-graded according to [15] and [17], since $C_{u}$ is greater than 4 and $C_{c}$ is between 1 and 3 .

\section{Conclusion}

A horizontal shaft hammer mill has been designed, fabricated with locally available materials and tested in this work. The performance evaluation gave a crushing capacity of $301 \mathrm{~kg} / \mathrm{h}$ for granite. The machine showed a theoretical through-put efficiency of 75.4 per cent. The products from crushing were found to be well graded with uniformity coefficient of 10.2 and an average coefficient of gradation of 1.89 .

\section{References}

[1] Egbe, E.A.P. and Olugboji, O.A. "Design, Fabrication and Testing of a Double Roll Crusher", International Journal of Engineering Trends and Technology (IJETT), vol. 35, no. 11, pp. 2231-5381, 2016.

[2] Nasir, A. "Development and Testing of a Hammer Mill", Assumption University: AU Journal of Technology, vol. 8, no. 3, pp. 124-130, 2005.

[3] Obojes, U., Tropper, P., Mirwald, P.W. and Saxer, A. "The Effects of Fire and Heat on Natural Building Stones: First Results from the Gröden Sandstone", Heritage, Weathering \& Conservation, vol. 1, no. 2005, pp. 521-525, 2006.

[4] Egbe, E.A.P. and Olugboji, O.A. "Design, Fabrication and Testing of a Double Roll Crusher", International Journal of Engineering Trends and Technology, vol. 35, no. 11, pp. 511-515, 2016.

[5] Richard, G.H. "Fundamentals of Particle Technology", Shepshed, Leicestershire, UK: Midland Information Technology and Publishing, 2002.

[6] Backhurst, J.R., Harker, J.H. and Richardson, J.F. "Coulson \& Richardson's Chemical Engineering Solutions to the Problems in Chemical Engineering", Oxford. UK: Butterworth-Heinemann, 2002.

[7] Deepak, G. "Design and Analysis of a Horizontal Shaft Impact Crusher", 10 March 2008. [Online]. Available: http://Ethesis.Nitrkl.Ac.In/2148/1/107ME037__Impact_Crusher.Pdf. [Accessed 16 June 2020]. 
[8] Kachalla, J.B. "Design and Fabrication of a Hammer Mill", Mechanical Engineering Department, Federal University of Technology, Minna, Niger State. Nigeria, 2011.

[9] Tesfaye, O.T. and Getaw, A.T. "Design of Impact Stone Crusher Machine", International Journal of Scientific \& Engineering Research, vol. 10, no. 5, pp. 904-909, 2019.

[10] Gupta, A. and Yan, D. "Mineral processing design and operation", USA: Elsevier, 2016.

[11] Mingqing, Y. "Strength Criterion for Rocks Under Compressive-Tensile Stresses and its Application," Journal of Rock Mechanics and Geotechnical Engineering, vol. 7, no. 4, p. 434-439, 2015.

[12] Lartey, D. "Energy Efficiency in Electrical Drive Systems: Technical Potentials, Barriers and Policy Approaches for Small and Medium Industries in Ghana", University of Technology, Faculty of Technology Electrical Engineering, Lapeenranta, Ghana, 2016.

[13] Khurmi, R.S. and Gupta, J.K. "A Textbook of Machine Design", New Delhi, India: S. Chand \& Company Ltd, 2005.

[14] Chukwuezie, O.C., Nwakuba, N.R. and Asoegwu, S.N. "Performance Analysis Of A Modified Laboratory Hammer Mill: Field Test Results From Different Tropical Crops", Polytechnica, vol. 4, no. 2020, pp. 1-12, 2020.
[15] Charles, C. "Mechanical Analysis of Soil", Civil Engineering Department, University of Memphis, Memphis, Tennessee. USA, 2016.

[16] Wills, B.A. and Napier-Munn, T.J. "Wills' Mineral Processing Technology: an Introduction to the Practical Aspects of Ore Treatment and Mineral Recovery", USA: Elsevier Science \& Technology Books, 2006.

[17] Sunil, K. "Soil Classification", Indian Institute of Technology Guwahati, Assam. India , 2009.

[18] Vishnudatt, A.S., Finkie, R.L., Goenopawiro, K. and WijngaardE, G.W. "The Performance of the H2 and H3 Hammer Mill in a Small Scale Gold Mining Operation a Case Study at the Kriki Negi Area District Brokopondo Suriname", Encontro Nacional de Tratamento de Minérios e Metalurgia Extrativa, vol. 4, no. 28, pp. 1-7, 2019.

[19] Hadi, M.I., Bawa, M.A., Dandakouta, H., Ahmed, M. and Kamtu, P.M. "Improvement on the Design, Construction and Testing of Hammer Mill", American Journal of Engineering Research (AJER), vol. 6, no. 3, pp. 139-146, 2017.

[20] Chris, W. “3 Benefits of a Hammer Mill”, 16 August 2017. [Online]. Available: http://www.3benefitsof .com/3-benefits-of-ahammer-mill/. [Accessed 18 June 2020]. 